\title{
CONHECER OS RISCOS, ADMINISTRAR A VIDA: ACONSELHAMENTO GENÉTICO ENTRE A BIOPOLÍTICA E A SOCIEDADE DE CONTROLE
}

\author{
Bruno Lucas Saliba de Paula \\ Yurij Castelfranchi
}

\begin{abstract}
RESUMO
Neste artigo, comparamos o modo de funcionamento do aconselhamento genético (AG) com as medidas eugênicas do século passado. Realizamos uma análise de materiais jornalísticos publicados no Brasil sobre o $\mathrm{AG}$, além de uma discussão teórica sobre as configurações do biopoder num contexto biotecnológico. Concluímos que, enquanto a eugenia era exercida por Estados que disciplinavam as condutas individuais e regulavam as populações para "melhorar a raça humana", o AG se aproxima da racionalidade da governamentalidade neoliberal e da sociedade de controle. Isso porque o AG se desenrola num contexto em que governo, mercado e especialistas modulam o campo de probabilidades e riscos aberto por indivíduos que, como "empreendedores de si mesmos", precisam administrar seu capital genético e são tidos como clientes e acionistas, além de pacientes e cidadãos.
\end{abstract}

Palavras-chave: Aconselhamento genético. Eugenia. Biopoder. Sociedade de controle.

\footnotetext{
${ }^{1}$ Mestre em Sociologia pela Universidade Federal de Minas Gerais (UFMG). Integrante do Observatório InCiTe - Inovação, Cidadania, Tecnociência/UFMG, Brasil. blsalibapaula@gmail.com

2 Professor do Departamento de Sociologia, Universidade Federal de Minas Gerais (UFMG). Coordenador do Observatório InCiTe - Inovação, Cidadania, Tecnociência/UFMG, Brasil. ycastelfranchi@gmail.com
} 


\title{
UNDERSTANDING THE RISKS, MANAGING LIFE: GENETIC COUNSELLING BETWEEN BIOPOLITICS AND SOCIETY OF CONTROL
}

\begin{abstract}
The aim of this paper is to compare the genetic counselling (GC) with the eugenic policies of the early twentieth century. We perform an analysis of how GC is portrayed by the Brazilian press as well as a theoretical discussion about the configurations of biopower in a biotechnological context. Our results indicate that while eugenics was practiced by States that disciplined individual conduct and regulated its populations to "improve the human race", the GC relates to the neoliberal governmentality's and to the society of control rationalities. It happens because the GC takes place in a context in which government, market and experts modulate the probabilities and risks associated to individuals who, as "entrepreneurs of themselves", need to manage their genetic capital and are considered as customers and stakeholders, and not only patients and citizens.
\end{abstract}

Keywords: Genetic counselling. Eugenics. Biopower. Society of control.

\section{INTRODUÇÃO}

6 6 favor da evolução e da vida", diz-nos o material publicitário de uma empresa especializada em biologia molecular e em exames genéticos. Cada vez mais comuns no Brasil, tais serviços pretendem avaliar com precisão a ocorrência ou o risco de ocorrência de doenças de causas genéticas em indivíduos específicos, seus familiares e futuros descendentes (BRUNONI, 2002; PINA-NETO, 2008). Esse conjunto de práticas se condensa no processo de aconselhamento genético (AG), uma especialidade surgida na década de 1950 que, desde então, não para de ganhar respaldo e adeptos na medicina.

A experiência da atriz norte-americana Angelina Jolie serve como exemplo dos mais emblemáticos. No dia 14 de maio de 2013, a artista anunciou, por meio de uma publicação no The New York Times intitulada "My medical choice", ter se submetido a uma mastectomia dupla preventiva a fim de reduzir suas chances de ter câncer. Sua decisão se pautou no resultado de um teste genético que revelara ser ela portadora de um gene "defeituoso", o BRCA1, responsável por um aumento significativo na probabilidade de desenvolvimento dos cânceres de mama e de ovário. "Quando tomei conhecimento dessa minha condição, decidi ser proativa e reduzir ao mínimo o risco", afirmou Jolie. 
Não obstante, é a partir dos casais que planejam ter filhos que se desenvolve uma das modalidades mais recorrentes de AG: aquela levada a cabo durante o período pré-concepcional ou no acompanhamento pré-natal. Ao longo de algumas consultas médicas e depois de exames físicos, casais em situação de risco se informam detalhadamente sobre as chances de que seus descendentes sejam acometidos por uma doença. Com base nas informações assim obtidas, livremente optarão, então, por ter ou não filhos.

Essas situações suscitam questões bastante delicadas. 0 que leva alguém a optar pela remoção dos seios para diminuir o risco de desenvolver câncer? Em que se baseia a decisão dos casais ao escolher ter ou não um filho (possivelmente) enfermo? Se preferem não dar à luz um bebê nessas condições, estariam perseguindo e sustentando tipos humanos tidos como normais e melhores? Somos levados, assim, a uma indagação mais abrangente: como se relacionam, na contemporaneidade, AG e eugenia? Procuramos responder essas perguntas, de um lado, através da análise de peças publicitárias de laboratórios de genética clínica e de matérias jornalísticas publicadas nos últimos quinze anos por veículos de ampla circulação no Brasil. Com isso, buscamos compreender os significados, representações, embates e controvérsias em torno do AG, traçando, ainda que preliminarmente, suas especificidades no contexto brasileiro contemporâneo. De outro lado, cotejamos tais investigações com dados históricos relativos à eugenia e à biologia, bem como com uma discussão teórica voltada às relações, tanto na primeira metade do século XX quanto nos dias que correm, entre ciência e Estado, sem desconsiderar os processos de constituição de subjetividades, as visões e posturas individuais que emergem nesses contextos frente aos saberes biomédicos e às relações de força do Estado com seus cidadãos.

Nossos resultados indicam que, uma vez que pertenciam ao seu escopo tanto de regular as populações, quanto de moldar as condutas e escolhas individuais, as políticas de eugenia adotadas no final do século XIX e início do XX por Estados ansiosos pela limpeza e pela otimização da raça humana podem ser consideradas, em termos foucaultianos, estratégias biopolíticas por excelência. Isso porque à anatomopolítica do corpo, praticada por um regime disciplinar que conforma e treina comportamentos e corpos individuais, vêm se agregar as técnicas de gerenciamento planificado da vida do homem-espécie, isto é, das populações. Ganham relevância fenômenos que emergem das dinâmicas populacionais, os quais podem ser descritos e administrados por meio de estatísticas e taxas (de natalidade, de mortalidade, epidemiológicas, etc.) referentes a uma coletividade (FOUCAULT, 2006). Tal estratégia biopolítica se baseou tanto nos discursos de verdade da biologia organicista quanto nas relações 
de poder de um Estado que, através de suas medidas de saúde pública, educava e comumente coagia - os indivíduos a se tornarem conscientes de seus hábitos de higiene, a cuidarem de seus corpos e a fazerem escolhas reprodutivas corretas. Em outras palavras, as políticas eugênicas formavam sujeitos "biologicamente prudentes" (ROSE, 2007, p. 24).

Por outro lado, o AG se vale de um contexto em que têm proeminência os saberes produzidos pela biologia molecular - cuja epistemologia informacional, sobretudo no contexto da sociedade de controle (DELEUZE, 2010), ganha contornos de uma "informática da dominação" (HARAWAY, 1991) -, assim como um Estado caracterizado pela racionalidade da governamentalidade neoliberal (FOUCAULT, 2006, 2008a). Reduzidos os encargos estatais, são as instituições privadas e os indivíduos que devem perseguir o bem-estar e a saúde. Lidaríamos hoje, de acordo com Michel Foucault, com uma configuração particular, marcada pela peculiar intersecção entre técnicas de dominação e técnicas de si (FOUCAULT, 1993), em que os indivíduos são concebidos e se vêem como agentes livres, autônomos e proativos, ávidos por investimentos em si próprios. Enquanto as políticas eugênicas eram grandes empreendimentos científico-estatais de cunho coercitivo, o AG seria levado a cabo por indivíduos livres e autônomos em busca da minimização dos riscos que podem acometê-los.

\section{A BIOLOGIA E SUAS MUTAÇÕES: O ORGÂNICO E INFORMACIONAL, O MOLDE E A MODULAÇÃO}

A eugenia se fundamentou numa biologia de cunho evolucionista e organicista empenhada em compreender os fenômenos vitais em nível macro. De acordo com Nikolas Rose (2007, p. 43-44), o modelo médico dominante para a compreensão do corpo era o de um "todo organicamente unificado", composto por órgãos e tecidos interconectados funcionalmente. Como sabemos - via Émile Durkheim e sua noção de "solidariedade orgânica", para citar apenas um exemplo -, essa perspectiva exerceu fortes influências sobre o pensamento social. A sociedade torna-se concebida em consonância com a noção de unidade funcional utilizada para tratar dos organismos vivos, a qual está constantemente sujeita a ameaças por disfunções capazes de perturbar a ordem vital. É exatamente essa correspondência entre o corpo individual e o corpo social que vai sustentar as idéias eugênicas.

Um dos primeiros tensionamentos nessa visão "molar" da vida e do corpo se deu na década de 1930, quando, pioneiramente, cientistas observaram 
processos vitais numa escala submicroscópica, entre $10^{-6}$ e $10^{-7} \mathrm{~cm}$ (ROSE, 2007, p. 44). Entretanto, foi só em 1953, com 0 artigo seminal de Watson \& Crick, que divulgava a descoberta da estrutura molecular tridimensional do DNA (artigo possibilitado pelas intuições fundamentais e pouco reconhecidas da biofísica Rosalind Franklin), que a concepção de vida foi redefinida, sendo associada a um "código". A partir daí, emerge na biologia o que Rose, na esteira de Georges Canguilhem, denomina "epistemologia informacional" - e que Donna Haraway (1991) recontextualiza como "informática da dominação". Não é mais necessário que os biólogos moleculares recorram apenas ao léxico da física e da química para estudar os processos orgânicos. Lançam mão, também, do vocabulário oriundo da linguística, da teoria da comunicação e da computação. Mensagens, informações, programas, transcrição, decodificação: uma reconfiguração do discurso e das práticas científicas, em que

ciências da comunicação e biologias modernas são construídas por um movimento comum - a tradução do mundo num problema de codificação, a busca de uma linguagem comum na qual toda resistência ao controle instrumental desaparece e toda heterogeneidade pode ser submetida à desmontagem, remontagem, investimento e troca (HARAWAY, 1991, p. 164 - tradução nossa).

Não por acaso, "ler o livro da vida" foi o que constituiu o manifesto retórico e programático do Projeto Genoma Humano, iniciado em 1990. Tecidos, células, organelas, atividades intracelulares, códigos de seqüência das bases de nucleotídeos e suas variações, os mecanismos que regulam a expressão e a transcrição gênicas, etc.: 0 objeto de estudos da biologia se tornava cada vez mais microscópico e, sobretudo, informacional. Ressignificada a vida, também a doença ganhava outras conotações, sendo concebida como um "defeito" de código. Como sinaliza Haraway (1991), há uma diferença profunda, por exemplo, entre o que significa infecção e tuberculose, no contexto do século XIX, e como é abordado e combatido o vírus da HIV, no século XXI. No primeiro caso, um Outro, um organismo non-self, um inimigo externo, precisa ser eliminado. No segundo, trata-se de tentar descodificar um retrovírus capaz de transcrever sua sequência no interior de nosso próprio programa genético, ou de evitá-lo por meio de ações de prevenção levada a cabos por indivíduos informados, prudentes, responsabilizados.

A partir do pós-guerra e com mais intensidade depois do fim da Guerra Fria, paralelamente a esta transformação epistêmica na biologia, assistimos a 
rupturas políticas e econômicas da genética. Os deslocamentos neoliberais contribuíram para formatar uma governamentalidade que já não se preocupa apenas com a gestão eficiente da vida e do trabalho de amplas categorias sociais ou com o planejamento sistemático de processos populacionais - através de medidas voltadas à seguridade social, a taxas de criminalidade, epidemiológicas, etc. Mais do que isso, a governamentalidade precisa lidar também com os efeitos e afetos de um indivíduo livre e proativo, tido como bomo oeconomicus neoliberal: um sujeito portador de interesses, "empreendedor de si mesmo" (FOUCAULT, 2008a). 0 indivíduo volta a ser um alvo importante, agora não só para ser vigiado e treinado, mas, ao contrário, como emissor de rastros, dados, desejos, comportamentos, que constituem outros tantos input e feedback cruciais para orientar a produção, o marketing e a política. Como acrescenta Gilles Deleuze (2010), novas configurações e necessidades conduzem a sociedade "de controle" a incorporar a sua moldagem auto-deformante que continuamente modifica a si mesma, metaestável e cibernética (estrutura que agora se sobrepõe aos moldes rígidos e estáticos da sociedade disciplinar), além de características sóciodemográficas e de desejos individuais, também elementos "dividuais" - como perfis e padrões de consumo, preferência, risco, etc. Nesse sentido, as medidas biopolíticas precisam, também, incitar e suscitar mecanismos em que cada indivíduo se responsabilize pela própria saúde e pelo planejamento de seu futuro, contribuindo para a modulação do mercado do qual é consumidor e da política na qual é cidadão.

Como na governamentalidade neoliberal, segundo Foucault (2008a), é a verdade que emana do mercado que perpassa e orienta as esferas do Estado, da sociedade civil e até mesmo as escolhas individuais, deparamo-nos com o ponto em que a biopolítica, mais do que nunca, penetra as entranhas da vida coletiva e individual. Não só a esfera social é redefinida como um domínio econômico. Se há um entrelaçamento entre discursos, produção de conhecimento, economias de poder e constituição do sujeito, a lógica econômica de custo e benefício seria utilizada também pelo pai de família ao administrar o lar, pelo aluno ao planejar sua trajetória acadêmica, enfim, pelo próprio indivíduo no cuidado que tem consigo. No neoliberalismo, "o bomo oeconomicus é um empresário, e um empresário de si mesmo, [...] sendo ele próprio seu capital, sendo para si mesmo seu produtor, sendo para si mesmo a fonte de [sua] renda" (FOUCAULT, 2008a, p. 311). Entretanto, além de racionais e calculistas, os indivíduos, em um contexto de governamentalidade, são vistos como desejantes. A liberdade e a atividade individuais são dados primeiros para essa racionalidade de governo, 0 que justifica seu empenho único em conhecer - e conduzir - os comportamentos 
e as imagens que cada um constrói em torno de si. Nesse sentido, às instâncias públicas interessa menos castigar e corrigir que atentar-se ao campo imanente das dinâmicas sociais e aos interesses e desejos de cada sujeito, seja de modo a incentivá-los ou desestimulá-los.

A governamentalidade envolve, então, dois movimentos: um de fora para dentro, em que o indivíduo é levado a se conformar às regras que the são exteriores; outro de dentro para fora, em que o sujeito age sobre si próprio (CASTELFRANCHI, 2008, p. 107). Qualquer um, a partir do momento em que passa a se definir como um empresário de si, pode considerar-se um capitalista, detentor inclusive de uma espécie peculiar de capital - o capital humano, isto é, um conjunto de investimentos feitos no nível do próprio homem. Dois são os tipos de capital humano na análise de Foucault (2008a, p. 312-317). Um deles é composto por elementos que podem ser adquiridos e que se tornam alvos dos mais ávidos investimentos. Enquadram-se, aí, boa forma física, autoestima elevada, "inteligência emocional", civilidade, bom gosto, qualificação profissional, etc.

0 outro tipo de capital humano é inato, diz respeito ao corpo e ao equipamento genético de cada um, os quais, por serem aparentemente imodificáveis, despertariam, se percebidos do ponto de vista da lógica econômica, um sentimento de impotência e resignação nos indivíduos. Todavia, Foucault (2008a, p. 313) percebe, já no desfecho da década de 1970, as rupturas micropolíticas e a abertura de bifurcações e potencialidades ligadas aos avanços na área da genética. Aplicada às populações humanas, a genética permite identificar os riscos a que cada indivíduo está submetido ao longo de sua existência. São esses saberes que possibilitariam intervir, de forma proativa, com espírito empreendedor, no supostamente inalterável capital humano inato ${ }^{3}$. Isso porque, uma vez reconhecidos aqueles indivíduos (ou embriões, no caso do diagnóstico pré-implantacional) que compõem um grupo de risco, é possível separá-los enquanto portadores de um "mau" material genético, daqueles que carregam um "bom" equipamento genético. Tais categorias, por sua vez, orientariam as escolhas conjugais, já que é a partir delas que os "empreendedores de si mesmo" tentariam administrar os riscos que podem acometê-los. Logo, inclusive a procriação humana pautar-se-ia em cálculos econômicos, já que o sujeito ansioso por ter um descendente cujo material genético seja tão bom ou melhor que o seu

\footnotetext{
${ }^{3}$ Para uma discussão mais detalhada acerca das implicações políticas da genética, bem como da capitalização e dos investimentos, proporcionados pelas novas tecnologias, no aparato biológico humano, ver a discussão feita por Osvaldo Lopez-Ruiz (2008).
} 
procurará casar-se com alguém que seja geneticamente privilegiado, ou adquirir óvulos ou esperma de indivíduos cujas chances de transmitir determinados traços genéticos são maiores ${ }^{4}$.

Foucault vislumbra, dessa forma, que no neoliberalismo o lugar da verdade e as discussões acerca das intervenções na genética humana dependem menos de preceitos morais fixos, transcendentes, e mais de táticas influenciadas por uma lógica de cunho econômico: é "em termos de constituição, de crescimento, de acumulação e de melhoria do capital humano que se coloca o problema político da utilização da genética" (FOUCAULT, 2008a, p. 314), e não em termos de um ideal, patrocinado pela ciência e pelo Estado, de refinamento biológico da humanidade. Em outras palavras, a invés da busca coletiva pelo aperfeiçoamento do homem através de práticas eugênicas, os próprios indivíduos se encarregariam de investir em seu capital biológico a fim de minimizar riscos (e dores) e maximizar as chances de ver concretizados seus desejos e planos.

Foucault chega a suas conclusões acerca da utilização da genética no final dos anos de 1970, momento em que ainda eram incipientes os avanços da engenharia genética e em que inexistiam a genômica e a proteômica. Somos levados a crer que, em boa medida, o diagnóstico do filósofo francês se aplica à contemporaneidade: 0 discurso do risco e da hereditariedade, as possibilidades abertas pelo $\mathrm{AG}$, as práticas dos sujeitos e as políticas públicas ligadas à saúde e à biotecnologia parecem fortemente atreladas a um dispositivo de tipo biopolítico em um contexto governamental neoliberal.

\section{ACONSELHAMENTO GENÉTICO}

0 AG nasce em estreita afinidade com a eugenia, mas, ao longo do seu desenvolvimento, busca se distinguir das consequências trágicas relacionadas a esta última - como as políticas de extermínio nazistas e as práticas de esterilização compulsória (em vários casos aprovadas por leis) por parte de países como EUA, Suíça, Suécia, etc. No Brasil, Renato Ferraz Kehl (1889-1974) foi um dos maiores expoentes do pensamento eugenista, que chegou a se

\footnotetext{
${ }^{4}$ Hoje, junto com as ferramentas já consideradas pelo filósofo francês, a terapia gênica promete modular e corrigir o capital biológico também em indivíduos adultos, além de possibilitar a seleção da herança biológica que transmitirão a seus descendentes (embora tal prática ainda não seja permitida por lei). Ademais, a biomedicina, em convergência com a nanotecnologia e as tecnologias informacionais, abre todo aquele campo de intervenções saudadas pelos movimentos trans-humanistas e do hiper-humano (MONTEIRO, 2012; PEPPERELL, 2003).
} 
institucionalizar com a Sociedade Eugênica de São Paulo, em 1918; com a Liga Brasileira de Higiene Mental, em 1923; e com a Comissão Central Brasileira de Eugenia, em 1931, para citar apenas alguns exemplos. 0 caso brasileiro, contudo, distingue-se dos demais por promover não tanto uma "eugenia negativa" - que diretamente impunha restrições à existência ou procriação de grupos tidos como inferiores -, mas uma eugenia de caráter "preventivo", mais ligada à profilaxia, ao sanitarismo e ao higienismo que ao racismo científico (SOUZA, 2007).

A própria concepção de AG mais amplamente adotada atualmente demarca bem suas diferenças em relação à eugenia. Referimo-nos à definição adotada desde 1975 pela American Society of Human Genetics, conforme a qual o AG consiste num processo de comunicação que lida com problemas humanos associados à ocorrência, ou ao risco de ocorrência, de alguma doença genética numa família (PINA-NETO, 2008, p. S22). Trabalham nesse processo profissionais de várias áreas treinados para ajudar indivíduos e/ou seus familiares a: compreender os fatos médicos e os tratamentos disponíveis; examinar como a hereditariedade exerce influências sobre distúrbios e qual é o risco de recorrência em parentes específicos; entender e avaliar as alternativas diante do risco de repetição de uma doença, principalmente aquelas que dizem respeito às decisões reprodutivas; escolher e ajustar-se às ações apropriadas (PINA-NETO, 2008, p. S22-S23; BRUNONI, 2002). Trata-se, portanto, de uma forma de informar 0 sujeito e de levá-lo a refletir sobre sua herança biológica, possibilitando que ele repense seu comportamento e seus planos em relação ao futuro.

Embora seja esse 0 entendimento predominante nos dias de hoje, o AG assumiu vários formatos ao longo do tempo. Alguns autores periodizam sua história, tal como ocorrida nos países desenvolvidos, em três períodos, cada qual com seus objetivos, problematizações, orientações normativas, técnicas e formas de agir sobre as condutas individuais (NOVAS \& ROSE, 2000, p. 492-495; ROSE, 2007, p. 114-116; PINA-NETO, 2008, p. S20-22). 0 primeiro período seria 0 eugenista, que, praticado nas décadas de 1930 e 1940, valia-se de técnicas diretivas ou mesmo coercitivas a fim de formatar escolhas conjugais $e$ reprodutivas.

0 segundo período refere-se à fase preventivista ou médica, que começou a ser praticada nos anos de 1950 e vigorou, grosso modo, até a década de 1970 . Foi aí que se consolidou a distinção entre o AG e a eugenia. 0 modelo preventivista já não tomava como fim o aprimoramento do estoque genético ou a manipulação dos movimentos reprodutivos humanos, mas pretendia apenas diminuir a incidência de certas enfermidades congênitas e otimizar a saúde da população - 
objetivos que só poderiam ser alcançados por meio de iniciativas voluntárias por parte dos indivíduos. Uma diferença marcante entre esse modo de funcionamento e o que o precedeu é a importância que começa a ser dada à neutralidade e à nãodiretividade na relação médico-paciente. Outra especificidade é a redução do foco do $\mathrm{AG}$ aos indivíduos e, no máximo, à sua família. A partir da fase preventivista, é o paciente que, com base em orientações médicas imparciais, voluntariamente decide tomar providências. Nasce, dessa forma, o ideal de "sujeito geneticamente responsável" (NOVAS \& ROSE, 2000).

Finalmente, o terceiro período de AG corresponde ao modelo psicossocial, exercido desde os anos de 1970 até os dias de hoje. Trata-se de um momento de grandes desenvolvimentos do conhecimento biomédico, em que aparecem novas técnicas, como os vários tipos de diagnóstico pré-implantacional e de acompanhamento pré-natal, empregados para detectar anomalias em embrióes ainda não implantados no útero materno e em bebês em gestação, respectivamente. Nessa fase, além da prevenção de doenças, torna-se comum a identificação e comunicação de riscos genéticos, ponto em que esse modelo converge com a prática, típica da governamentalidade, de uma gestão fundamentada nos conceitos de risco e de campos de probabilidade, conforme a qual passam a interessar os fenômenos prováveis relativos à população (crimes, desemprego, migrações, doenças, etc.), os quais devem ser ajustados através de dispositivos de segurança que regulam fluxos e riscos associados a cada acontecimento (FOUCAULT, 2008b). 0 modelo psicossocial de AG converge também com as novas formas assumidas pelas ciências no final do século XX, que priorizam uma produção de conhecimentos orientada a problemáticas específicas, à possibilidade de aplicá-los e à inter e transdisciplinaridade (NOWOTNY et al, 2001; CASTELFRANCHI, 2008).

Outra peculiaridade do modelo psicossocial é o intenso envolvimento e participação tanto dos conselheiros quanto dos seus clientes ${ }^{5}$. Estes são, cada vez mais, incitados a desempenhar um papel ativo durante o processo de AG. Mais do que nunca, a consulta envolve indivíduos autônomos fazendo escolhas esclarecidas e responsáveis quanto aos seus futuros. Ao contrário de uma relação verticalizada - que demarca a superioridade de um expert transmissor de informações a um leigo, que as recebe passivamente -, a sessão de AG passa a ser

\footnotetext{
${ }^{5}$ Optamos por preservar, aqui, o termo "cliente", utilizado pela própria literatura médica ao tratar do AG: a transição de um cidadão-paciente, alvo e receptor de dispositivos disciplinares e de práticas biomédicas, para um proativo stakeholder-cliente, típico da governamentalidade neoliberal, é significativa.
} 
vista como um processo dinâmico, no qual conselheiro e cliente se ajudam mutuamente.

\section{DO CORPO DIVIDIDO: VIDA-CÓDIGO}

Indícios das reconfigurações ocorridas com a biologia e com a genética podem ser encontrados em propagandas de empresas brasileiras atuantes no âmbito da genética clínica. Na divulgação da GENETICENTER (fig. 1), por exemplo, um centro de AG privado operante em Minas Gerais e São Paulo, há elementos da narrativa textual e imagética bastante expressivos. As quatro bases nitrogenadas que compõem a estrutura codificante do DNA (A - adenina, G - guanina, C citosina, T - timina), as "letras" constituintes do "alfabeto da vida", são apresentadas de forma simbolicamente relevante: como blocos parecidos com os de jogos infantis. Todos eles pintados com cores "independentes" (vermelho, azul, verde e amarelo), e não como nuances de uma mesma cor. Representam, assim, unidades que são elementares, mas passíveis de recombinações. Como tijolos utilizados numa construção, as bases nitrogenadas podem ser compostas e recompostas em diversas sequências e formas. Processo que não se dá sem incertezas, riscos e probabilidades, elementos expressados pelos cubos que também lembram dados utilizados em jogos. Toda essa operatoriedade está associada, na propaganda e no discurso genômico, a diferentes programações de um organismo "dividual".

FIGURA 1 - Apresentação da empresa GENETICENTER.

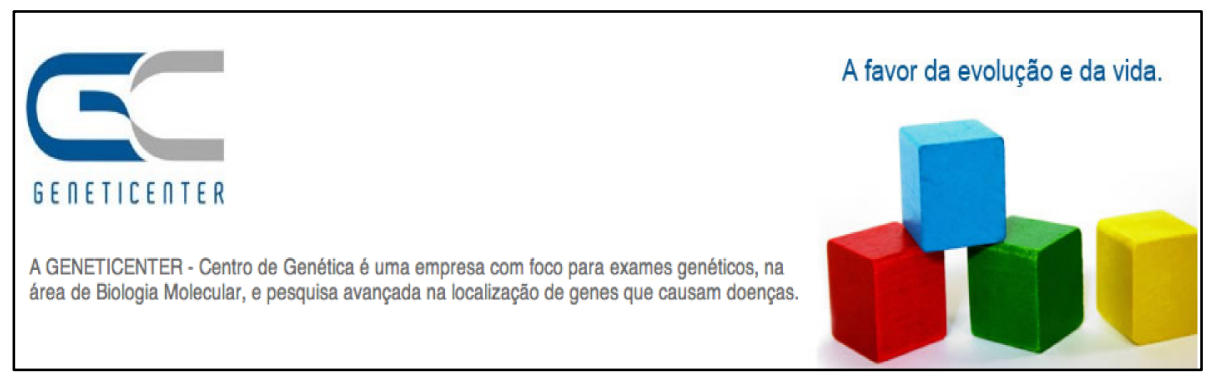

Fonte: GENETICENTER ${ }^{6}$

${ }^{6}$ Disponível em: <http://www.geneticenter.com.br/> . Acesso em 12 de novembro de 2012. 
A GENETICENTER trabalha, através do exame e da produção de recombinações, "a favor da evolução e da vida", como diz seu slogan. De propósito amplo e vago, o slogan não deixa de aproveitar a ambiguidade do campo semântico da palavra "evolução", entendida em dois sentidos: de um lado, o aspecto biológico - que pode ser alvo de intervenções graças à expertise tecnocientífica da empresa, mas que entendido literalmente não seria necessariamente cativante para o "cliente", vítima em potencial da seleção natural; de outro lado, o sentido amplo, mais atraente em sua conotação de progresso, avanço, melhoria. Também a palavra "vida" ganha significações específicas, reinterpretada pela imagem (tal como pela genômica) em termos moleculares e informacionais. Finalmente, na medida em que a vida se torna um "código", a doença assume um novo estatuto ontológico, diretamente relacionado aos genes e marcado por uma dimensão probabilística. Conforme a concepção presente no site da empresa: "acreditamos que a medicina do futuro passa obrigatoriamente pela genética, pois por meio dela poderemos cuidar de doenças que na prática ainda não se manifestaram, porém por questões biológicas podemos afirmar que já existem"”.

Narrativas como a acima analisada são indicativos de uma transformação: noções caras à eugenia - como população, qualidade, e raça - parecem ter perdido espaço nos dias que correm. Os efeitos de verdade que habitam 0 território do molecular, do informacional e do probabilístico (e já não tanto o do molar, do orgânico e do campo de forças) direcionam 0 alvo da governamentalidade para o "dividual" (DELEUZE, 2010), quer dizer, para perfis de risco mais do que para o corpo individual desviante ou para a gestão territorialpopulacional em nível macro. A biopolítica da população, amparada na estatística e funcionando conforme uma lógica epidemiológica, continua importante: as políticas de saúde coletiva ainda estabelecem como fim o bem-estar da nação como um todo. A diferença, contudo, é que a qualidade do aparato biológico ou da saúde de uma população é medida não tanto em termos de perigos políticos, biológicos ou morais (como era quando o que estava em jogo era "degeneração da raça", a "decadência da espécie"), mas principalmente em termos "econômicos": de fluxos, riscos, custos e benefícios.

Identificamos essa transformação no discurso do $\mathrm{AG}$ e, de maneira mais geral, não é difícil ver esse deslocamento também no funcionamento da epidemiologia e da saúde pública, como no caso, por exemplo, do DALY

\footnotetext{
${ }^{7}$ Disponível em: < http://www.prolabnet.com.br/credenciadas.php?k=166>. Acesso em 12 de novembro de 2012.
} 
(Disability-adjusted life year). Trata-se de uma das unidades de medida internacionalmente utilizadas na área de saúde pública para qualificar e classificar o peso e a gravidade das doenças, a partir de um indicador que junta de forma híbrida mortalidade e morbidade, estimando os efeitos de doenças (incapacidade ou mortes causadas) em termos abstratos de "número de anos perdidos". Nesses termos, é possível comparar epidemiologicamente (e conforme a lógica da biopolítica, em termos de custos sociais) o impacto de condições extremamente diferentes, como doenças infecciosas, que causam mortes de forma direta, problemas públicos de saúde mental ou determinados padrões de risco social, que podem não afetar de forma direta e imediata a sobrevivência e a capacidade dos indivíduos, mas estão ligadas a perdas sociais calculadas em termos de anos de trabalho produtivo perdidos, por exemplo ${ }^{8}$. Além disso, o entendimento da saúde pública com base em fluxos e riscos se manifesta também a partir de uma concepção em que a qualidade do aparato biológico e a saúde são, do ponto de vista ontológico, localizadas menos no organismo individual e mais na informação, em seus padrões e facetas dividuais; e, do ponto de vista político, incentivadas a partir de intervenções que pretendem modular não apenas fenômenos de massa (campanhas de vacinação, de higiene pública), mas também padrões de desejos e afetos do bomo oeconomicus.

Como consequência direta desse processo, menos que adotar medidas coercitivas e disciplinantes, o governo, hoje, foca mais na ativação de atores particulares, seja por meio do estímulo de desejos e interesses ou de sensos de moralidade - que envolvem culpa ou a radicalização das responsabilidades por si mesmo, sobretudo num contexto de individualização da existência (BECK \& BECKGERNSHEIM, 2003). Cada vez mais, os deveres quanto ao bem-estar cabem, também, às instituições privadas e aos indivíduos. Empresas e organizações são incitadas a assegurar a saúde de seus empregados e membros. Semelhantemente, cada cidadão se torna um parceiro do Estado ao ser convocado a monitorar seu corpo e sua saúde (ROSE, 2007, p. 63-64). Trata-se, prioritariamente, de constituir, acumular e fazer render capital humano. A medicina genômica, em geral, e o AG, especificamente, seriam instrumentos indispensáveis para a consecução de tais metas.

8 A esse respeito, ver a definição do DALY na Wikipedia. Disponível em: < https://en.wikipedia.org/wiki/Disability-adjusted_life_year > . Acesso em 19 de junho de 2015. 
FIGURA 2 - 0s cinco "pês" da medicina genômica, conforme o professor Sérgio Pena.

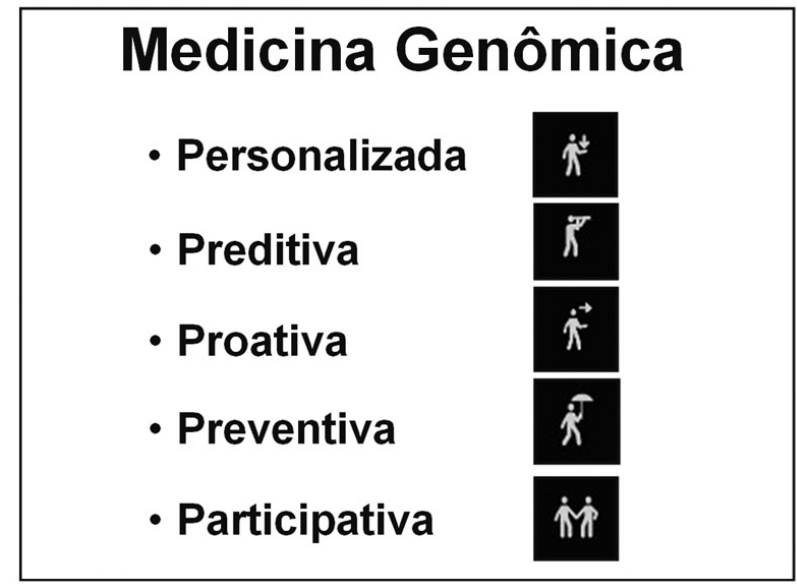

Fonte: "Medicina genômica é uma revolução em curso, diz Sérgio Pena". Notícias da $U F M G-34 / 11 / 2010^{9}$

No Brasil, tais deslocamentos biopolíticos podem ser percebidos com a exploração empírica de elementos discursivos sobre o AG, sobretudo aquele oferecido pelo mercado. É curioso observar, por exemplo, como as caraterísticas atribuídas à medicina genômica pelo geneticista Sérgio Pena (fig. 2) se relacionam a alguns dos mecanismos que conferem especificidade à economia-política contemporânea. A "personalização" diz respeito à adequação dos diagnósticos e tratamentos às necessidades e desejos de um cliente-consumidor único, de forma semelhante ao funcionamento da produção e do marketing no capitalismo pósfordista. A "proatividade" se refere ao dever do bomo oeconomicus de agir com vista à minimização dos riscos a que está submetido e à elevação de seu bemestar. A "participação" nos remete à centralidade do paciente em sua relação com o médico. Indícios de uma racionalidade política-econômica que traz o indivíduo para primeiro plano, não para discipliná-lo, mas para suscitá-lo a atuar voluntariamente. Por fim, o caráter "preditivo" e o "preventivo" reportam à prática de governo via campos de probabilidade, construídos com base em estatísticas populacionais e bancos de dados informacionais (ponto em que 0 indivíduo dá lugar à população ou ao elemento “dividual”).

9 Disponível em: < https://www.ufmg.br/online/arquivos/017443.shtml>. Acesso em 8 de novembro de 2012 . 


\section{ACONSELHAMENTO GENÉTICO NA IMPRENSA BRASILEIRA}

Para cartografar, de forma exploratória, o modo operatório da biopolítica relacionada à saúde - e mais especificamente à medicina genômica - no contexto brasileiro, debruçamo-nos sobre o material publicado acerca do AG por alguns jornais do país, a saber, Folha de S. Paulo, O Estado de São Paulo e G1-O Portal de Notícias da Globo. Através das ferramentas de busca disponibilizadas nos portais desses veículos, construímos uma base de dados com matérias contendo a expressão "aconselhamento genético" (com aspas). Não fizemos nenhuma alteração nos parâmetros de pesquisa já estabelecidos pelos sites. Assim, obtivemos um banco de dados empírico composto pelo conjunto de todas as reportagens publicadas desde 0 ano de 2000 por três dos maiores veículos jornalísticos do país. Trata-se de 55 reportagens, sendo: 27 da Folha de S. Paulo, abarcando o período compreendido entre 4 de setembro de 2000 e 15 de agosto de 2012; 19 de 0 Estado de São Paulo, que vão de 4 de maio de 2001 a 28 de novembro de 2012; e 9 do G1, de 11 de dezembro de 2006 a 13 de dezembro de 2012.

A partir desse corpus, procuramos identificar no discurso jornalístico elementos narrativos recorrentes e associações entre campos semânticos de termos frequentemente utilizados, além de detectar a presença e o tipo de atores envolvidos, como cientistas, políticos e pacientes. Também no nível discursivo, buscamos evidenciar quais mecanismos de legitimação ou invalidação seriam mobilizados por esses agentes, bem como encontrar categorias argumentativas e leitmotifs narrativos, tais como os relacionados às expectativas em torno das novas tecnologias, ao dever moral que os pacientes em situação de risco têm de adequarem suas condutas, ao papel do Estado frente a questões de saúde pública, aos dilemas éticos acerca das aplicações da genômica, etc. A análise qualitativa foi efetuada a partir da codificação dos elementos textuais por parte dos autores, que utilizaram o software de Computer Assisted Qualitative Data Analysis (CAQDA) "QDA Miner"

Um primeiro resultado da análise aponta para uma interessante coexistência de práticas e camadas discursivas. Embora tenhamos identificado

\footnotetext{
10 O mesmo software também possibilita análises quali-quantitativas, que nos permitiram identificar indícios de associações particularmente recorrentes entre argumentações, temas ou leitmotifs narrativos, associações que, por sua vez, auxiliaram a interpretação e o aperfeiçoamento de nossas categorias de análise. Não obstante, dada sua complexidade e levando em conta que fugiríamos do escopo deste trabalho, não entraremos nos detalhes da análise estatística (lexicográfica, de clusters e de redes semânticas).
} 
várias familiaridades entre o modo de funcionamento do $\mathrm{AG}$ - sobretudo a partir do modelo "psicossocial" - e a lógica da governamentalidade neoliberal, aparecem, nos textos jornalísticos analisados, elementos e indícios de práticas normalizadoras ou disciplinares por parte do Estado. Seria o caso das leis voltadas a normalizar e regulamentar a liberdade de decisão do indivíduo, cujas escolhas agora se dão com base em novas tecnologias que permitem diagnosticar precocemente doenças genéticas:

\begin{abstract}
"Se você detecta mais problemas mais cedo na gestação, a probabilidade de a mulher optar por um aborto aumenta", diz Jaime King, professora de Direito da Universidade da Califórnia em Hastings [...]. Vários Estados americanos vêm regulamentando o aborto de forma mais restritiva nos últimos anos. Quatro deles [...] proibiram a prática por motivo de sexo ou raça (cor da pele) do bebê, e há várias iniciativas legais também para torná-la ilegal quando motivada por anomalias físicas ou genéticas. (FONTE: "Genoma ao nascer: quem quer saber?” O Estado de São Paulo - 28/11/2012).
\end{abstract}

Mesmo assim, essas controvérsias não são suficientes para abrir mão da liberdade individual, desde que exercida com discernimento.

Para Jaime, isso [a possibilidade de que os testes genéticos aumentem o número de abortos] não é necessariamente um problema, desde que a decisão de abortar seja tomada de forma informada e consciente. "0 que a maioria das pessoas teme é que as mulheres recebam informações equivocadas ou confusas e acabem decidindo por um aborto com base em conclusões erradas. Isso seria realmente trágico". (FONTE: "Genoma ao nascer: quem quer saber?" O Estado de São Paulo - 28/11/2012).

Interessante notar que, ainda de acordo com o excerto acima, o problema é que nem sempre os sujeitos estão preparados para fazer as "melhores" escolhas, o que coloca em questão um dos princípios mais fundamentais do AG contemporâneo - a participação ativa dos pacientes ${ }^{11}$. Essa visão de que falta aos "leigos" capacidades cognitivas necessárias para a tomada de decisões corretas é,

\footnotetext{
${ }^{11}$ Um debate bastante prolífico sobre o exercício da autonomia reprodutiva frente a situações controversas, nas quais os pais não fazem as escolhas mais "adequadas", como no caso de casais integrantes da comunidade surda que manifestam preferência por filhos surdos ao recorrerem a tecnologias reprodutivas, pode ser encontrado no artigo de Débora Diniz (2003).
} 
aliás, típica da ordem discursiva disciplinar. Daí a afinidade de seus enunciados com os modelos tecnocráticos de "déficit" (CASTELFRANCHI, 2002), segundo os quais as falhas na "alfabetização científica" do público devem ser compensadas com formas de comunicação e informação do tipo top-down, em que a ciência produz conhecimento, o cientista e o Estado "sabem" e educam indivíduos carentes de informações.

0 teste genético pode detectar a tendência que uma pessoa tem de desenvolver uma doença antes que ela se manifeste. Mas os especialistas alertam que não é o tipo de exame recomendado para qualquer pessoa. [...] Os especialistas só se preocupam com uma febre por testes genéticos, que já prolifera até na internet. (FONTE: "Teste genético detecta tendência a desenvolver doenças". G1 - 14/07/09).

Nos casos atravessados por controvérsias ou incertezas científicas, chama a atenção que o "déficit" passa a se aplicar, também aos especialistas. Não apenas os pacientes, mas também os médicos, quando vistos pelo olhar dos geneticistas e dos cientistas, podem estar desinformados e incapazes de lidar com o avanço e a aceleração tecnocientífica.

De acordo com Kinsgmore, a principal questão associada a esse tipo de teste [que detecta doenças hereditárias a partir do sequenciamento genômico], para que ele seja disseminado, é a educação dos médicos e do público sobre as informações genéticas: como interpretá-las e como aplicá-las. "Isso vai requerer o treinamento de muitos conselheiros genéticos", disse o pesquisador. (FONTE: "Exame de sangue da mãe detecta síndrome de Down”. Folha de S. Paulo - 13/01/2011).

Embora conotações e enunciações remetentes a uma tecnociência "de disciplina" (CASTELFRANCHI, 2008) estejam presentes no discurso midiático, elas não constituem a regra. Muito mais freqüentes e extensos são os indícios de que as relações entre sujeitos, ciência e políticas públicas são moduladas de acordo com uma lógica operatória típica da biopolítica e de uma racionalidade governamental neoliberal. Principalmente, pela presença predominante da estatística e de campos de probabilidades como elementos cruciais para orientar políticas públicas e práticas médicas. No trecho abaixo, a geneticista Mayana Zatz expõe um dos motivos para que exames genéticos sejam incluídos no SUS: 
"Há cem anos, nos Estados Unidos, de cada 1.000 crianças que nasciam, 150 morriam no primeiro ano de vida e, dessas, 5 eram por doença genética - cerca de $3 \%$. Hoje, de cada 1.000 crianças nascidas, 9 morrem no primeiro ano de vida e 5 de doenças genéticas. Passou a corresponder a $50 \%$ das mortes. Quanto mais se controlam as doenças infecciosas e sociais maior é o peso das doenças genéticas. E no Brasil estamos chegando a um número parecido com esse". (FONTE: "Mulher tem direito à informação". O Estado de São Paulo 10/01/2009).

Numerosos excertos dizem da necessidade de implementação de exames e AG no sistema público de saúde também a partir estatísticas e de cálculos probabilísticos.

No início da década de 80, elas [anomalias congênitas] respondiam por $5 \%$ do total de mortes na faixa etária [menos de um ano], contra $13 \%$ na última avaliação - situação que se mantém atualmente e com tendência de crescimento. [...] "Essas estatísticas podem ser consideradas surpreendentes, considerando sua magnitude e a total ausência de políticas governamentais relacionadas à prevenção e 0 manejo desse grupo de problemas", afirmaram os pesquisadores que realizaram o estudo. (FONTE: "Anomalias congênitas são $2^{\mathrm{a}}$ causa de mortes infantis". O Estado de São Paulo - 04/07/2008).

Notamos, então, que questões de saúde pública são definidas a partir de estatísticas e estudos comparativos e históricos, tendo como objeto a massa populacional. Raramente o foco das ações do governo é o indivíduo. Pretende-se, na maioria das vezes, agir sobre índices, como mostra a tentativa de reduzir a incidência de certas doenças e, consequentemente, a taxa de mortalidade a elas relacionada. As investigações preditivas e os dados probabilísticos constituem outros fatores de peso que influenciam a tomada de decisões e 0 estabelecimento de prioridades por parte do Estado. É a partir de argumentos que defendem a ação sobre índices, a diminuição de riscos e 0 incremento da eficiência que é justificada a inclusão do AG no SUS.

Além de definida em termos de rapidez, abrangência, capacidade, precisão, etc., à eficiência também é atribuída uma dimensão, digamos, econômica. Os cálculos de custo e benefício, próprios da governamentalidade neoliberal, frequentemente orientam as escolhas do governo: 
Além de evitar que mais pessoas padeçam de doenças evitáveis causadas por consanguinidade, o aconselhamento genético sai mais barato aos cofres públicos. No caso dos pacientes de mucopolissacaridose, [...] o tratamento de um tipo da doença pode chegar a R\$ 100 mil por mês, por paciente. (FONTE: "Sertão da Paraíba tem surto de doenças genéticas; casamento entre primos é a causa". Folha de S. Paulo - 21/11/2010).

As sugestões de que as descobertas na área de medicina genômica estariam sendo apropriadas pelo mercado é outro indicativo de afinidade entre a governamentalidade neoliberal e os usos dos saberes produzidos pela biologia molecular. Em alguns casos, há um curioso entrelaçamento, no interior da matéria jornalística, entre a descrição da medicina genômica personalizada e sua apropriação pelo mercado, contexto em que o paciente se revela também um cliente e consumidor. Antes e mais do que como um avanço no conhecimento técnico ou científico, a medicina personalizada tende a ser associada a um serviço ou produto.

Testes de DNA vendidos diretamente ao consumidor, que prometem conselhos de nutrição elaborados especialmente para combinar com os genes do cliente, não têm valor médico nenhum e podem enganar 0 consumidor, determinou uma investigação do Congresso dos Estados Unidos. [...] Não obstante, na internet e em algumas lojas dos Estados Unidos, pode-se comprar kits que permitem ao consumidor enviar ao fornecedor amostras de DNA, um questionário preenchido e receber aconselhamento nutricional. (FONTE: "EUA alertam contra testes genéticos para dieta". O Estado de São Paulo - 27/07/2006).

A apropriação do conhecimento científico pelo mercado não é feita sem ressalvas. Parece haver um contraste entre a medicina personalizada apropriada pelo mercado, tida como superficial e pouco confiável, e a medicina personalizada exercida por experts, retratada como mais séria. Dentro do hospital ou de outros espaços institucionais e coordenada e controlada por cientistas e médicos, as tecnologias são positivas e têm um potencial benéfico. 0 problema é quando elas são oferecidas diretamente ao cliente leigo, circunstância em que é indevidamente utilizada pelo mercado.

Finalmente, emergiram indícios de uma ordem discursiva em que enunciados relativos à ideia de "risco" são percebidos como associados aos que abordam a ideia de "autogoverno". Em algumas das matérias analisadas emerge 
com particular clareza a ênfase em um dos aspectos relevantes da constituição de subjetividade na governamentalidade neoliberal: indivíduos já não dóceis, disciplinados e normalizados, mas proativos, empreendedores e "prudentes", que tomam suas próprias decisões informadas e planejam suas escolhas de modo a aceitar e a calcular riscos, governando, dessa forma, a si mesmos. Em alguns casos, essa dinâmica é complementada pela postura e pelas intervenções dos médicos, que ratificam ou estimulam a iniciativa dos pacientes:

Quando se descobre a mutação nos genes, todos os cuidados precisam ser tomados para que a doença não se desenvolva. [...] Ações drásticas às vezes são necessárias. Dependendo do prognóstico, recomenda-se a retirada antecipada da mama ou do intestino, por exemplo. São casos em que nenhum tratamento seria capaz de evitar a evolução da doença e a morte do paciente. (FONTE: "Mais atenção ao câncer hereditário". O Estado de São Paulo - 23/11/2007)

\section{CONCLUSÕES}

Seria uma ingenuidade ver apenas pela perspectiva da eugenia o AG de hoje, embora ambos manifestem condições de possibilidade e lógicas parecidas, bem como a duplicidade e complementaridade de estratégias, ora disciplinares, ora biopolíticas. Majoritariamente, contudo, o AG se nos apresenta como um processo bem articulado à racionalidade da governamentalidade neoliberal e da sociedade de controle deleuziana. Não só as estatísticas populacionais, mas também os comportamentos individuais (e os rastros "dividuais", como genes, padrões e fatores de riscos, tendências comportamentais de grupos específicos, etc.) se tornam imprescindíveis ao arranjo de saber-poder ligado à medicina genômica.

No entroncamento do homem com as tecnologias genéticas e com relações

de poder que são, de uma só vez, políticas e econômicas, disciplinares, da governamentalidade e do controle, novas formas de vida parecem em vias de nascer. Não basta, por isso, analisar os aspectos econômicos, as políticas públicas e as racionalidades de governo para dar conta do AG. Devemos nos debruçar, igualmente, sobre os processos de subjetivação contemporâneos. Nossas análises sugerem a emergência de uma identidade biomedicalizada a envolver sujeitos calculistas, livres e responsáveis, empreendedores e prudentes (ROSE, 2007, p. 111). Além disso, identificamos, em relação ao AG contemporâneo, indícios que apontam para uma dinâmica caracterizada por dois movimentos. De um lado, 
fluxos que se dão, digamos, "de baixo para cima" - o Estado, longe de perseguir o melhoramento biológico da nação, apenas gere a população e os campos de probabilidade a partir do exame constante dos fluxos de seus cidadãos. Por outro lado, movimentos que ocorrem "de dentro para fora" - os sujeitos agem sobre si próprios e engendram modos de subjetivação ajustados aos jogos de verdade e às relações de poder. Acreditamos, todavia, que bifurcações e dissidências são produzidas na densidade desse imbricamento entre biomedicina, neoliberalismo e subjetividades contemporâneas, nuances que esperamos explorar mais detidamente em trabalhos futuros.

\section{REFERÊNCIAS}

BECK, Ulrich; BECK-GERNSHEIM, Elisabeth. La salud y la responsabilidad en la era de la tecnología genética. In: BECK, Ulrich; BECK-GERNSHEIM, Elisabeth. $L a$ individualización. El individualismo institucionalizado y sus consecuencias sociales y políticas. Barcelona: Paidós Ibérica, 2003.

BRUNONI, Décio. Aconselhamento Genético. Ciência e saúde coletiva, v. 7, n. 1, São Paulo, 2002, p. 101-107.

CASTELFRANCHI, Yurij. Scientists to the streets. Science, politics and the public moving towards new osmoses. JCOM - Journal of Science Communication, v. 1, n. 2, Trieste, junho de 2002, p. 1-14.

CASTELFRANCHI, Yurij. As serpentes e o bastão: tecnociência, neoliberalismo inexorabilidade. Tese de Doutorado, Sociologia, Universidade Estadual de Campinas, 2008.

DELEUZE, Gilles. Post-scriptum sobre as sociedades de controle. In: DELEUZE, Gilles. Conversações: 1972-1990. Rio de Janeiro: Ed. 34, 2010.

DINIZ, Débora. Autonomia reprodutiva: um estudo de caso sobre a surdez. Cad. Saúde Pública, v. 19, n. 1, Rio de Janeiro, janeiro/fevereiro 2003, p. 175-181.

FOUCAULT, Michel. About the Beginning of the Hermeneutics of the Self: Two Lectures at Dartmouth. Political Theory, v. 21, n. 2, may 1993, p. 198-227.

FOUCAULT, Michel. A governamentalidade. In: FOUCAULT, Michel. Microfísica do poder. Rio de Janeiro: Graal, 2006.

FOUCAULT, Michel. Nascimento da biopolítica: curso dado no Collège de France (1978-1979). São Paulo: Martins Fontes, 2008a. 
FOUCAULT, Michel. Segurança, território, população: curso dado no Collège de France (1977-1978). São Paulo: Martins Fontes, 2008b.

HARAWAY, Donna. A Cyborg Manifesto: Science, Technology, and SocialistFeminism in the Late Twentieth Century. In: HARAWAY, Donna. Simians, Cyborgs and Women: The Reinvention of Nature. New York: Routledge, 1991.

LEWIS, R. Barry; MAAS, Steven. QDA Miner 2.0: Mixed-Model Qualitative Data Analysis Software. Field Methods, v. 19, n. 1, February 2007, p. 87-108.

LOPEZ-RUIZ, Osvaldo. A técnica como capital e o capital humano genético. Novos estudos - CEBRAP, n. 80, março de 2008, p. 127-139.

MONTEIR0, Marko. Os dilemas do bumano: reinventando o corpo numa era (bio)tecnológica. São Paulo: Annablume, FAPESP, 2012.

NOVAS, Carlos; ROSE, Nikolas. Genetic risk and the birth of the somatic individual. Economy and Society, v. 29, n. 4, november 2000, p. 485-513.

NOWOTNY, Helga; SCOTT, Peter; GIBBONS, Michael. Rethinking science: knowledge and the public in an age of uncertainty. Cambridge: Polity Press, 2001. PEPPERELL, Robert. The Posthuman Condition: consciousness beyond the brain. Bristol: Intellect, 2003.

PINA-NETO, João Monteiro. Aconselhamento genético. Jornal de Pediatria (Rio J.), v. 84, n. 4, Porto Alegre, agosto de 2008, p. S20-S26.

ROSE, Nikolas. Politics of life itself: biomedicine, power, and subjectivity in the twenty-first century. Princeton: Princeton University Press, 2007.

SOUZA, Vanderlei. Em nome da raça: a propaganda eugênica e as idéias de Renato Kehl nos anos 1910 e 1920. Revista de História Regional, v. 11, n. 2, UEPG, 2007, p. 29-70.

\section{MATÉRIAS CITADAS}

“Anomalias congênitas são $2^{\text {a }}$ causa de mortes infantis" - O Estado de São Paulo, 04/07/2008. Disponível em:

$<$ http://www.estadao.com.br/noticias/geral,anomalias-congenitas-sao-2-causa-demortes-infantis,236157> . Acesso em 15 de dezembro de 2012.

"EUA alertam contra testes genéticos para dieta" - O Estado de São Paulo, 27/07/2006. Disponível em: < http://www.estadao.com.br/noticias/geral,eua- 
alertam-contra-testes-geneticos-para-dieta,20060727p64021>. Acesso em 15 de dezembro de 2012.

"Exame de sangue da mãe detecta síndrome de Down" - Folha de S. Paulo, 13/01/2011. Disponível em:

<http://www1.folha.uol.com.br/fsp/saude/sd1301201101.htm > . Acesso em 15 de dezembro de 2012.

"Genoma ao nascer: quem quer saber?" - O Estado de São Paulo, 28/11/2012.

Disponível em: < http://ciencia.estadao.com.br/blogs/herton-escobar/genoma-aonascer-quem-quer-saber/> . Acesso em 15 de dezembro de 2012.

"Mais atenção ao câncer hereditário" - O Estado de São Paulo, 23/11/2007.

Disponível em: < http://vida-estilo.estadao.com.br/noticias/geral,mais-atencao-aocancer-hereditario,84292> . Acesso em 15 de dezembro de 2012.

"Mulher tem direito à informação" - O Estado de São Paulo, 10/01/2009.

Disponível em: < http://vida-estilo.estadao.com.br/noticias/geral,mulher-temdireito-a-informaca0,305412> . Acesso em 15 de dezembro de 2012.

"Sertão da Paraíba tem surto de doenças genéticas; casamento entre primos é a causa" - Folba de S. Paulo, 21/11/2010. Disponível em:

$<$ http://www1.folha.uol.com.br/ciencia/2010/11/833820-sertao-da-paraiba-temsurto-de-doencas-geneticas-casamento-entre-primos-e-a-causa.shtml > . Acesso em 15 de dezembro de 2012.

"Teste genético detecta tendência a desenvolver doenças" - G1, 14/07/09.

Disponível em: < http://g1.globo.com/bomdiabrasil/0,,MUL1228835-16020,00TESTE + GENETICO + DETECTA + TENDENCIA + A+DESENVOLVER+DOENCAS.ht $\mathrm{ml}>$. Acesso em 15 de dezembro de 2012. 